\title{
ESTABILIDADE EM LONGO PRAZO DO RETALHO POSICIONADO CORONALMENTE PARA RECOBRIMENTO RADICULAR EM FUMANTES E NÃO FUMANTES
}

Ana Paula BONOTTO, Bruna Maggioni TEIXEIRA, Eduardo Augusto Galbiatti MUNCINELLI, Keila RODRIGUES, Cleverson de Oliveira SILVA

A recessão gengival (RG) é comum na maioria das populações, sendo mais freqüente em fumantes (Martinez-Canut et al., 1995; Gunsolley et al., 1998; Calsina et al., 2002). Este estudo objetivou avaliar o efeito do tabagismo em longo prazo nos resultados do recobrimento radicular pela técnica de retalho posicionado coronalmente (RPC). Foram tratadas recessões Classe I de Miller em canino ou pré-molares superiores de 10 pacientes fumantes há mais de 5 anos e 10 não-fumantes. As mensurações foram realizadas depois de 6, 12 e 24 meses, e os parâmetros clínicos eram: profundidade de sondagem (PS), nível clínico de inserção (NCl), recessão gengival e quantidade de tecido queratinizado (TQ). A análise intragrupo mostrou que a RPC não conseguiu manter a margem gengival alcançada nos primeiros seis meses. O recobrimento radicular aos 6 meses foi significativamente maior em não-fumantes $(91,3 \%)$ do que em fumantes $(69,3 \%)$. De acordo com o teste de Wilcoxon $(\alpha=0,05)$, a $R G$ aumentou significativamente em fumantes (de 0,84 $\pm 0,49 \mathrm{~mm}$ para $1,28 \pm 0,58 \mathrm{~mm}$ ) e em não-fumantes (de $0,22 \pm 0,29 \mathrm{~mm}$ para $0,50 \pm 0,41 \mathrm{~mm}$ ), entre 6 e 24 meses. $50 \%$ dos fumantes e $10 \%$ dos não-fumantes perderam entre 0,5 e $1,0 \mathrm{~mm}$ de cobertura radicular nesse período. Ambos perderam $\mathrm{NCl}$, sendo mais visível em fumantes $(1,58 \mathrm{~mm} \pm 0,75 \mathrm{~mm}$ para $2 \mathrm{~mm} \pm 0,75 \mathrm{~mm}$ ) e diminuíram o TQ (. Em longo prazo, a estabilidade do RPC é inferior a desejável, especialmente em fumantes. Dois anos após um procedimento RPC, os fumantes têm significativamente maior recessão residual em comparação aos não-fumantes, estatisticamente (Testes de Wilcoxon e de Fisher) e clinicamente.

Palavras-chave: Recessão; Tabagismo; Inserção. 